\title{
Penetrating eye injuries in pediatric population: An epidemiological study and visual outcome
}

\author{
Kabindra Bajracharya ${ }^{1}$, Salma K C Rai ${ }^{2}$, Arjun Malla Bhari ${ }^{3}$, Hari Bahadur Thapa ${ }^{4}$, \\ Anjita Hirachan ${ }^{5}$, Saraswati Pandey ${ }^{6}$, Davide Borroni ${ }^{7}$ \\ ${ }^{1}$ Assistant Professor, ${ }^{2}$ Professor, ${ }^{3}$ Pediatric Ophthalmologist, ${ }^{4}$ Optometrist, Department of Pediatric Ophthalmology and \\ Strabismus, Lumbini Eye Institute, Bhairahawa, Nepal, ${ }^{5}$ Resident, Department of Ophthalmology, Universal College of \\ Medical Sciences, Bhairahawa, Nepal, ${ }^{6}$ Fellow, Department of Pediatric Ophthalmology and Strabismus, Lumbini Eye \\ Institute, Bhairahawa, Nepal, ${ }^{7}$ Resident, Department of Ophthalmology, Riga Stradins University, Riga, Latvia
}

A B S T R A C T

Background: Penetrating eye injury is an important cause of visual impairment in pediatric population. Aims and Objectives: The study was done to evaluate the epidemiology and visual outcome of penetrating eye injuries in pediatric population. Materials and Methods: This retrospective study was conducted at the Department of Pediatric Ophthalmology and Strabismus, Lumbini Eye Institute from June 2014 to May 2015. All patients of penetrating eye injuries up to the age of 15 years were included in the study. The demographics of the patient, cause and duration of injury, the presenting and final best corrected visual acuity, anterior and posterior segment findings were recorded in specially designed proforma. Results: A total number of 127 children (127 eyes) presented with penetrating eye injuries during a year. The incidence of penetrating eye injury in one year was 127 out of 12927 new patients. Minimum age was 11 months, while the maximum age was 15 years with mean of 7.29 years $(S D= \pm 3.49)$. Male and female patients were $99(78 \%)$ and $28(22 \%)$ respectively. Involvement of right eye was seen in 69 cases $(54.33 \%)$ and left eye $58(45.67 \%)$. The most common cause of injury was wooden stick in 55 cases $(43.31 \%)$ followed by iron wire $12(9.45 \%)$ and the stone $11(8.66 \%)$. Corneal laceration was found in 102 cases $(80.31 \%)$, scleral laceration in $10(7.87 \%)$ and corneo-scleral laceration in $15(11.81 \%)$. Seventy three percent patients were blind at the time of presentation whereas at discharge $37.63 \%$ were blind and $11.43 \%$ of patients had visual acuity better than $6 / 18$ at presentation whereas $35.48 \%$ had visual acuity better than $6 / 18$ after treatment. Conclusion: Penetrating eye injury is one of the common causes attending Pediatric Ophthalmology Department. These injuries are common in male and majority of trauma is caused by wooden stick. The awareness of ocular trauma and its consequences should be increased to reduce childhood blindness.

Access this article online

Website:

http://nepjol.info/index.php/AJMS

DOI: 10.3126/ajms.v7i4.14690

E-ISSN: 2091-0576

P-ISSN: 2467-9100

Key words: Penetrating eye injuries, Epidemiology, Visual outcome

\section{INTRODUCTION}

Eye injury is one of the major causes of visual impairment in pediatric population. There are 1.6 million people blind from eye injuries, 2.3 million people with bilateral low vision and 19 million cases of monocular blindness world-wide. ${ }^{1}$ Children are more prone to injuries because of their inability to avoid hazards. ${ }^{1}$ In general male are more frequently reported to have eye injuries as compared to female due to their adventurous and aggressive nature. ${ }^{2}$ In Nepal, National survey conducted by HMG, WHO/PBL in 1981 has shown blindness due to ocular trauma is $2.4 \% .^{3}$ Trauma is no doubt one of the most important preventable causes of childhood blindness. ${ }^{4}$ Ocular trauma is an important cause of monocular blindness worldwide. ${ }^{5}$

Address for Correspondence:

Dr. Kabindra Bajracharya, MD, MA, Assistant Professor and Pediatric Ophthalmologist, Pediatric Ophthalmology and Strabismus 
The objective of this study was to determine the epidemiology and visual outcome of penetrating eye injuries in pediatric population presented to Lumbini Eye Institute, the tertiary eye hospital of western Nepal, who were admitted and surgically managed.

\section{MATERIALS AND METHODS}

This retrospective study was conducted at the Department of Pediatric Ophthalmology and Strabismus, Lumbini Eye Institute over a period of one year from June 2014 to May 2015. All patients of penetrating eye injuries up to the age of 15 years were included in the study. A chart review was performed collecting from medical record department. Information collected for this study included age, sex, cause of injury, duration of injury before presentation, eye injured, visual acuity at presentation, ocular morbidity, and best corrected visual acuity at the last follow-up visit which was recorded in specially designed proforma. This study was approved by the Ethical Review Board of the hospital.

Data analysis was performed using SPSS version 20. The age was analyzed by descriptive method with mean \pm standard deviation. The variables were analyzed as frequency and percentages.

\section{RESULTS}

A total number of 127 children (127 eyes) presented with penetrating eye injuries during a year. The incidence of penetrating eye injury in one year was 127 out of 12927 new patients. Minimum age of presentation was 11 months, while the maximum age was 15 years with mean of 7.29 years $(\mathrm{SD}= \pm 3.49)$. Male and female patients were $99(78 \%)$ and $28(22 \%)$ respectively with male to female ratio of 3.5:1. The most common age group was 5-10 years with 61 cases $(48.32 \%)$ (Table 1).

Children attended with minimum of 6 cases in the month of September to maximum of 14 cases in the month of February (Figure 1).

Fifty three patients (41.7\%) were from Nepal and $74(58.3 \%)$ from India. All of the cases presented with unilateral involvement. The right eye was affected in $69(54.33 \%)$ and left eye $58(45.67 \%)$ of patients. The most common cause of injury was wooden stick $55(43.31 \%)$, followed by iron wire $12(9.45 \%)$ and the stone $11(8.66 \%)$ (Table 2).

The patients presented within 24 hours were $43(33.9 \%)$ whereas $79(62.2 \%)$ patients presented within 72 hours. Wounds were predominantly corneal in 102 cases $(80.31 \%)$, scleral laceration in 10 cases $(7.88 \%)$ and corneo-scleral laceration in 15 cases $(11.81 \%)$ (Table 3$)$.

Iris prolapse or incarceration was present in $58(45.6 \%)$ of patients. Traumatic cataract was present in $44(34.6 \%)$, lens was clear in 15 (11.8\%) and undetermined in 68 (53.5\%) patients. The patients underwent surgery under general anaesthesia in $121(95.3 \%)$ of patients. Twenty seven patients $(21.3 \%)$ were operated on same day of presentation and $56.7 \%$ were operated on second day of presentation.

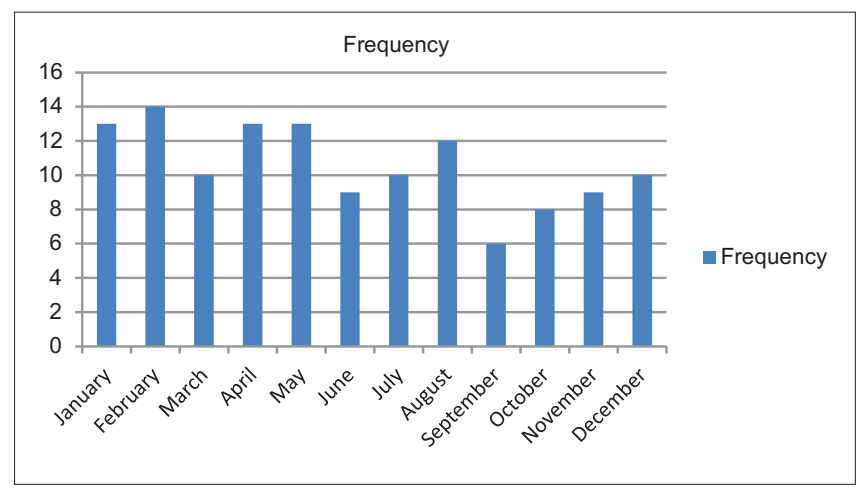

Figure 1: Distribution of patients according to the month of presentation

\begin{tabular}{|c|c|c|c|c|}
\hline \multirow{2}{*}{$\begin{array}{l}\text { Age group } \\
\text { in years }\end{array}$} & \multicolumn{2}{|c|}{ Sex } & \multirow[t]{2}{*}{ Total } & \multirow[t]{2}{*}{ Percentage } \\
\hline & Male & Female & & \\
\hline$<1 \mathrm{yr}$ & 0 & 1 & 1 & 0.79 \\
\hline $1-5$ & 34 & 9 & 43 & 33.86 \\
\hline $5-10$ & 47 & 14 & 61 & 48.32 \\
\hline $10-15$ & 18 & 4 & 22 & 17.32 \\
\hline Total & 99 & 28 & 127 & 100 \\
\hline
\end{tabular}

\begin{tabular}{lcc}
\multicolumn{3}{l}{ Table 2: Objects causing penetrating eye injury } \\
\hline Objects causing trauma & Frequency & Percentage \\
\hline Wooden stick & 55 & 43.31 \\
Iron wire/metallic piece & 12 & 9.45 \\
Stone/brick & 11 & 8.66 \\
Pen/pencil & 7 & 5.51 \\
Needle & 5 & 3.94 \\
Glass & 5 & 3.94 \\
Unknown & 5 & 3.94 \\
Fall & 4 & 3.15 \\
Knife & 4 & 3.15 \\
Bird beak & 4 & 3.15 \\
Nail & 3 & 2.36 \\
Lighter gas & 2 & 1.58 \\
Bicycle chain & 2 & 1.58 \\
Scissors & 2 & 1.58 \\
Head band & 2 & 1.58 \\
Top/laddu & 1 & 0.78 \\
Cd cassette & 1 & 0.78 \\
Door knob & 1 & 0.78 \\
File & 1 & 0.78 \\
Total & 127 & 100 \\
\hline
\end{tabular}


Fifty one patients $(72.86 \%)$ among 70 visual acuity documented patients had $<3 / 60$ at presentation and socially blind. In this study WHO definition of blindness has been considered which defines best corrected visual acuity in better eye $<3 / 60$ and in Nepal it is categorized as social blindness. ${ }^{6}$ Eight $(11.43 \%)$ patients had visual acuity better than 6/18 (Table 4), which has been categorized as mild or no visual impairment. ${ }^{6}$

At the time of discharge 35 (37.63\%) out of 93 visual acuity documented patients had $<3 / 60$ and were socially blind. Thirty three (35.48\%) had visual acuity better than $6 / 18$ after treatment (Table 5).

\begin{tabular}{lcc}
\multicolumn{3}{l}{ Table 3: Site of laceration } \\
\hline Site of laceration & Frequency & Percentage \\
\hline Corneal laceration & 102 & 80.31 \\
Corneoscleral laceration & 15 & 11.81 \\
Scleral laceration & 10 & 7.88 \\
Total & 127 & 100 \\
\hline
\end{tabular}

\begin{tabular}{lcc}
\multicolumn{3}{c}{ Table 4: Unaided visual acuity at presentation } \\
\hline Visual acuity & Frequency & Percentage \\
\hline $6 / 6$ & 1 & 0.8 \\
$6 / 9$ & 3 & 2.4 \\
$6 / 12$ & 2 & 1.6 \\
$6 / 18$ & 2 & 1.6 \\
$6 / 24$ & 1 & 0.8 \\
$6 / 36$ & 1 & 0.8 \\
$6 / 60$ & 8 & 6.3 \\
$3 / 60$ & 1 & 0.8 \\
$1 / 60$ & 13 & 10.2 \\
HM & 19 & 15 \\
PL & 18 & 14.2 \\
NPL & 1 & 0.8 \\
Undetermined & 57 & 44.9 \\
Total & 127 & 100 \\
\hline HM: Hand movement, PL: Perception of light, NPL: No perception of light
\end{tabular}

HM: Hand movement, PL: Perception of light, NPL: No perception of light

\section{Table 5: Final BCVA after treatment}

\begin{tabular}{lcc}
\hline Visual acuity & Frequency & Percentage \\
\hline $6 / 6$ & 7 & 5.5 \\
$6 / 9$ & 13 & 10.2 \\
$6 / 12$ & 7 & 5.5 \\
$6 / 18$ & 6 & 4.7 \\
$6 / 24$ & 2 & 1.6 \\
$6 / 36$ & 6 & 4.7 \\
$6 / 60$ & 10 & 7.9 \\
$3 / 60$ & 7 & 5.5 \\
$2 / 60$ & 3 & 2.4 \\
$1 / 60$ & 11 & 8.7 \\
HM & 5 & 3.9 \\
PL & 13 & 10.2 \\
NPL & 3 & 2.4 \\
Undetermined & 34 & 26.8 \\
Total & 127 & 100 \\
\hline BCVA: Best corrected visual acuity & &
\end{tabular}

The globe integrity was maintained in 104 cases (81.9\%) and $23(18.1 \%)$ eyes went phthisical.

\section{DISCUSSION}

Ocular trauma is often the most important cause of unilateral loss of vision particularly in developing countries. ${ }^{5}$ The incidence of penetrating eye injury in one year in this study was 127 out of 12927 new patients. Mean age was of 7.29 years $(\mathrm{SD}= \pm 3.49)$.

The most common age group was 5-10 years comprising $48.32 \%$. This is the age group when children start playing independently and at the same time not aware of consequences of ocular injury. In the study done by Dulal S et $\mathrm{al}^{7} 38.1 \%$ of ocular injury was found in this age group. Maurya R P et al ${ }^{8}$ found $43.9 \%$ in this group.

Fifty three patients $(41.7 \%)$ were from Nepal and $74(58.3 \%)$ from India. Due to location of our hospital in boarder, both Indian and Nepali patients were coming for ocular treatment and due to availability of full time anesthesiologist; it has been referral center for many western part of eye care centers of Nepal.

In our study male and female patients were $99(78 \%)$ and $28(22 \%)$ respectively with male to female ratio of $3.5: 1$ which was similar to study done in Nigeria and Nepal. ${ }^{10}$ The ratio was 1.8:1 to 8:1 in one study. ${ }^{5}$ Dulal $S$ et al ${ }^{7}$ found $62 \%$ trauma in male as compared to $38 \%$ in females and Godar ST et $\mathrm{a}^{11}$ found $66.5 \%$ male. In a study done in Pakistan ${ }^{12} 72.25 \%$ were male and in the study done by Poon ASY et al $^{13} 73.3 \%$ were male. Male predominance may be due to their more aggressive nature and greater exposure to outward mobility given to them.

All of the cases presented with unilateral involvement. Involvement of right eye was higher in our study $54.33 \%$ which was similar to right eye predominance found in many studies. ${ }^{5,11}$ But in the study done by Bukhari et al ${ }^{14} 52.9 \%$ and Dulal et $\mathrm{al}^{7} 51.8 \%$ left eye involvement was common.

The most common cause of injury was wooden stick $43.31 \%$ followed by iron wire $9.45 \%$ and the stone $8.66 \%$. Most of the children have habit of playing with sticks and accidental injury is common. The patients presented within 24 hours were $33.9 \%$. In the study done by Malik I Q et $\mathrm{al}^{12} 20 \%$ of ocular injuries were presented on first day.

In this study $21.3 \%$ patients were operated on same day and $87.4 \%$ were operated within second day of presentation. The anatomical integrity and visual outcome depends on the surgery performed after trauma. Early surgery is concern for both patients and surgeon. The patients 
underwent surgery in general anaesthesia in 121 (95.3\%). The pediatric patients, as far as possible, should be operated on general anesthesia to avoid psychological stress as well as comfort for surgeon too.

Seventy three percent patients were blind at the time of presentation whereas at discharge $37.63 \%$ were blind and $11.43 \%$ of patients had visual acuity better than $6 / 18$ at presentation whereas $35.48 \%$ had visual acuity better than 6/18 after treatment.

\section{CONCLUSION}

Penetrating eye injury is one of the common causes attending Pediatric Ophthalmology Department. Penetrating eye injury is common in male and majority of trauma is caused by wooden stick. The awareness of ocular trauma and its consequences should be increased to reduce incidence of childhood blindness.

\section{REFERENCES}

1. Negrel $A D$ and Thylefors $B$. The global impact of eye injuries. Ophthalmic Epidemiol 1998; 5:143-169.

2. Neranen M and Raivio I. Eye injuries in Children. Br J Ophthalmol 1981; 65:436-438.

3. Brillant LB, Pokhrel RP, Grasset NC, Lepkowski JM, Kolstad A, Hawks W, et al. Epidemiology of Blindness in Nepal. Bull World
Health Organ 1985; 63:375-386.

4. Mulvihil A, Bowell R and Lanigan B. Uniocular Childhood Blindness a Prospective Study. J Pediatr Ophthalmol Strabismus 1997; 34:111-114.

5. Cillino S, Cauccio A, Di Pace F, Pillitteri F and Cillino G. A five-year retrospective study of the epidemiological characteristics and visual outcomes of patients hospitalized for ocular trauma in a Mediterranean area. BMC Ophthalmol 2008; 8:6: 1-9.

6. Sapkota YD. The Epidemiology of Blindness in Nepal: 2012. Nepal Netra Jyoti Sangh. Nepal 2012; 9.

7. Dulal S, Ale JB and Sapkota YD. Profile of pediatric ocular trauma in mid-western hilly region of Nepal. Nepal J Ophthalmol 2012; 4(7): 134-137.

8. Maurya RP, Singh VP, Yadav I, Singh MK, Mishra CP, Sen PR, et al. Profile of pediatric ocular trauma at a tertiary eye care centre in Northern India. Indian Journal of clinical and Experimental Ophthalmology 2015; 1 (2): 7-1.

9. Oluyemi F. Epidemiology of Penetrating Eye Injury in Ibadan: A 10-Year Hospital-Based Review. Middle East Afr J Ophthalmol 2011; 18(2): 159-163.

10. Karki DB. Ocular morbidity due to trauma. PMJN 2008: 8(1): 6 .

11. Godar ST, Kaini KR, Amatya P, Joshi K and Singh L. Magnitude of ocular trauma in a tertiary care hospital of western Nepal. Nepal Journal of Medical Sciences 2013; 2 (2): 141.

12. Malik IQ, Ali Z, Rehman A, Moin M and Hussain M. Epidemiology of Penetrating Ocular Trauma. Pak J Ophthalmol 2012; 28(1): 14-16.

13. Poon ASY, Ng JSK, Lam DSC, Fan DSP and Leung ATS. Epidemiology of severe childhood eye injuries that required hospitalization. HKMJ 1998; 4(4): 371-374.

14. Bukhari S, Mahar PS, Qidwai U, Bhutta IA and Memon AS. Ocular Trauma in Children. Pak J Ophthalmol 2011: 27 (4): 208-212.

Authors Contribution:

KB- Concept and design of the study, reviewed the literature, collected data, statistically analyzed and interpreted, manuscript preparation, editing and revision of the manuscript; SKR- Concept, prepared first draft of manuscript; AMB- Concept, reviewed the literature; HBT- Data analysis; AH- Concept and design of the study, collected data; SP- Data collection; DB- Data analysis, reviewed literature

Source of Support: Nil, Conflict of Interest: None declared. 